\title{
A EDUCAÇÃO AMBIENTAL NOS CURSO TÉCNICOS INTEGRADOS AO ENSINO MÉDIO DO CAMPUS PENEDO - IFAL: ANÁLISE DOS LIVROS DIDÁTICOS DE LIINGUA PORTUGUESA E A CONSTRUÇÃO DE CARTILHA AMBIENTAL ${ }^{1}$
}

\author{
Adriano de Souza Freitas ${ }^{2}$ \\ Denise Regina da Costa Aguiar ${ }^{3}$ \\ Cristina Veloso Castro ${ }^{4}$
}

Resumo: A Educação Ambiental (EA) é um processo contínuo, permanente e interdisciplinar, está relacionada à cultura, à ética, à economia, à política e à ecologia. Sendo isso considerado, este trabalho pretende analisar como a (EA) está introduzida nos livros didáticos (LD) de Língua Portuguesa (LP) adotados pelo campus Penedo (IFAL). A metodologia da investigação é documentalbibliográfica de cunho exploratório, subsidiada por Freire $(1979,1986,1987$, 2000, 2006 a\&b), Reigota (2014), Guimarães (2014), Loureiro (2014) e Marcuschi (2008). Considerou-se que os LD tratam da EA de maneira superficial/introdutória no aspecto qualitativo, assim, foi confeccionado um paradidático, proposta interventiva em uma perspectiva crítico-emancipatória

Palavras-chave: Educação Ambiental; Língua Portuguesa; Livro Didático; Paradidático; Paulo Freire.

${ }^{1}$ Este trabalho foi preparado especialmente para cumprir um critério para obtenção do título de mestre. Trata-se de uma síntese da dissertação, produto final para obtenção do título. 2 Instituto Federal de Alagoas. E-mail: adrifreitas23@gmail.com 3 Universidade Brasil. E-mail: costaag@uol.com.br 4 Universidade Brasil. E-mail: cristina.castro@universidadebrasil.edu.br Revbea, São Paulo, V. 14, № 2: 306-327, 2019. 


\section{Introdução}

A Educação Ambiental (EA) é um processo contínuo, permanente e interdisciplinar, está relacionada à cultura, à ética, à economia, à política, ao social e à ecologia, subsidia o sujeito e, consequentemente, a comunidade. Assim, levando tudo isso em consideração se propõe analisar um recurso pedagógico importante e tão presente nas escolas, o livro didático. Para estruturar melhor essa introdução do artigo, serão vistos de maneira sucinta: (1) o que é Educação Ambiental e qual tipo está sendo relevado, (2) os objetivos: geral e específicos, (3) a problemática, a justificativa e sua delimitação, (4) a base teórica (fundamentação), isto é, o que se sabe desse assunto, principalmente, no tocante as últimas pesquisas relevantes sobre a temática - o que normalmente é chamado de estudo da arte ou correlato. Obras pertinentes como livros e textos jurídicos serão ressaltados, ao passo que as demais serão destacadas na seção Material e Método.

\section{O que é Educação Ambiental?}

Quando se fala a um leigo sobre Educação Ambiental (EA), com certeza, ele já associa à mata, à floresta, à queimada, ao lixo espalhado pela cidade etc. Não está, de maneira ampla, equivocado, porém se sabe que é uma ideia superficial ou limitada da grande área que é a EA. Ademais, se for perguntado sobre qual disciplina (componente curricular) deve se ater a passar, discutir, incrementar esse conhecimento educacional, provavelmente, este leigo responderá que a Biologia, Ciências, Geografia e, talvez, História tenham essa "função". Excepcionalmente, uma pessoa refletirá sobre o que é, de fato, Educação Ambiental e perceberá que esse "conteúdo" tão importante deve ser tratado em todos os componentes e, além disso, deve ser trabalhado de maneira associativa, isto é, com "o pluralismo de ideias e concepções pedagógicas, na perspectiva da inter, multi e transdisciplinaridade" (BRASIL, 1999, p.1). Como diz Guimarães, "A EA apresenta uma nova dimensão a ser incorporada ao processo educacional, trazendo toda uma recente discussão sobre as questões ambientais, e as consequentes transformações de conhecimento, valores e atitudes diante de uma nova realidade a ser construída" (2013, p.9).

Necessariamente, a Educação Ambiental aqui destacada é garantida por leis e defendida por pertinentes teóricos, por exemplo, Torres , “(...) garantam o desenvolvimento de atributos da EA no contexto escolar, como a perspectiva interdisciplinar, crítica e problematizadora; a contextualização; a transversalidade; os processos educacionais participativos; a consideração da articulação entre as dimensões local e global" (TORRES, 2010, apud LOUREIRO; TORRES, 2014, p.14), e Reigota, "(...) a educação ambiental deve ser entendida como educação política, no sentido de que ela reivindica $e$ prepara os cidadãos e as cidadãs para exigir e construir uma sociedade com justiça social, cidadanias (nacional e planetária), autogestão e ética nas relações sociais e com a natureza" (REIGOTA, 2014, p.14). Há ainda textos 
legislativos que institucionalizam a EA, por exemplo, Resolução no 2, de 15 de jun de 2012, que estabelece as Diretrizes Curriculares Nacionais para a Educação Ambiental, e LEI no 9.795, de 27 de abr. de 1999, que dispõe sobre a Política Nacional de Educação Ambiental. Deixa-se em detrimento uma EA convencional e fragmentada, para concentrar-se numa EA voltada para um processo crítico, criativo, disseminador de conhecimento; pautada na contígua relação entre seres humanos e estes e natureza; sobretudo, conscientizadora e participativa, Guimarães (2013) legitimada esses princípios:

Apenas a ação gera um ativismo sem profundidade, enquanto apenas a reflexão gera uma imobilidade que não cumprirá com a possibilidade transformadora, já dizia Freire. Em razão disso, dá-se grande importância ao papel participativo, atuante do educado/educador na construção do processo de EA, envolvendo-se integralmente, domínio afetivo e cognitivo, com a realidade apresentada, vivenciando-a criticamente para atuar na construção de uma nova realidade desejada. Essa posição contrapõe-se aos atuais processos educacionais que predominam nas escolas brasileiras, em que há uma concepção viciosa de colocar a ação em segundo plano, priorizando a transmissão de informações teóricas pela racionalidade sem atentar para a emoção. Limita-se assim à esfera teórica, sem agir na prática (GUIMARÃES, 2013, p.32)

Assim, a Educação Ambiental aqui investigada não está preocupada apenas com vertente ecológica - mesmo essa sendo bem pertinente -, no entanto, sim mais debruçada sobre as questões políticas, pois essas estão mais estreitas com a questão do livro didático, cerne desta pesquisa.

Uma EA menos ortodoxa e específicas das matas, dos animas e, portanto, dos impactos diretos causados pelos homens, está-se preocupado em realmente perceber como o Homem, sobretudo, o jovem está recebendo informações acerca da EA, se ela possui essência cidadã e promotora de mudanças. Nessa mesma perspectiva Reigota (2014) afirma:

Quando afirmamos e definimos a educação ambiental como educação política, estamos afirmando que o que deve ser considerado prioritariamente na educação ambiental é a análise das relações políticas, econômicas, sociais e culturais entre a humanidade e a natureza $e$ as relações entre os humanos, visando a superação dos mecanismos de controle e de dominação que impedem a participação livre, consciente e democrática de todos. A educação ambiental como educação política está comprometida com a ampliação da cidadania, da liberdade, da autonomia e da intervenção direta dos cidadãos e das cidadãs na busca de soluções e alternativas que permitam a convivência digna e voltada para o bem comum (REIGOTA, 2014, p.13) 


\section{Os objetivos: geral e específicos}

O objetivo central da pesquisa foi analisar a temática da Educação Ambiental nos livros didáticos de Língua Portuguesa utilizados no Ensino Técnico integrado ao Ensino Médio, no Instituto Federal de Alagoas (IFAL), bem como construir um material paradidático complementar.

A partir do objetivo central, procurou-se responder a objetivos específicos:

> Entender a Educação Ambiental em uma perspectiva críticoemancipatória e a possibilidade de trabalhar pedagogicamente com a temática nas aulas de Língua Portuguesa a partir do que destacam os pesquisadores e os arcabouços legislativos.

> Compreender melhor a finalidade do livro didático e a que ele se propõe, bem como catalogar/tabular todos os gêneros que tenham como cerne a temática ambiental.

> Considerar as últimas pesquisas acerca da Educação Ambiental nas perspectivas do livro didático de Língua Portuguesa e da abordagem freireana.

> Analisar material paradidático para construção de uma cartilha, para nortear o trabalho da Educação Ambiental em uma perspectiva críticoemancipatória no componente curricular de Língua Portuguesa.

\section{A problemática, a justificativa e sua delimitação}

Levantou-se como hipótese que o livro didático ${ }^{5}$ abordam as questões ambientais de maneira superficial, por isso a necessidade de ser mais profícuo com a criação de um material paradidático, corroborando também a ideia de desenvolver a crítica, a criatividade e construção de conhecimentos significativos para a vida dos estudantes.

\section{Fundamentação}

Sabendo que a fundamentação se trata de um debate que visa identificar opiniões, realizar críticas e fazer reflexões, esta seção foi realizada nas seguintes perspectivas para sistematizar as elucubrações: Relevância do tema e estado da arte (Levantamento Bibliográfico de Dissertações); Levantamento bibliográfico atinente à Educação Ambiental; Levantamento bibliográfico legislativo e documentos oficiais; Levantamento bibliográfico de Língua Portuguesa. Esta prática se deu por se tratar de uma pesquisa que está relacionada, sobretudo, a três grandes áreas: Educação Ambiental, Língua Portuguesa (Livro didático e teóricos) e Paulo Freire.

${ }^{5}$ Foram analisados os livros da série Ser Protagonista, objeto de estudo da pesquisa. 


\section{Relevância do tema e estado da arte}

Para perceber as principais temáticas e de que maneira as análises estão ocorrendo, foram realizadas entre, principalmente, os dias 10 e 18 de novembro de 2017 buscas no Catálogo de Teses e Dissertações da Coordenação de Aperfeiçoamento de Pessoal de Nível Superior - Capes. Foram inseridas as combinações: (1) Educação Ambiental no livro didático, (2) Educação Ambiental no livro didático de Língua Portuguesa e (3) Educação Ambiental e Paulo Freire. Para a primeira busca, o resultado foi de 834.672, ao passo que na segunda busca foram encontrados 986.992 e na última foram encontrados 985.284 resultados, portanto, notório o número elevado de trabalhos concluídos nas áreas afins aqui investigada. Assim foi realizada uma triagem, selecionadas, sobretudo, dissertações dos anos de 2016 e 2017, sendo analisadas entre 10 e 50 páginas do catálogo, sabendo que em cada página há 20 resultados, foram lidos entre 200 e 1000 títulos e resumos na plataforma Sucupira, todavia, o objetivo era analisar proficuamente cerca de 20 trabalhos de cada agrupamento. Pode-se destacar, sucintamente, no tocante ao primeiro bloco: pesquisas direcionadas à agua, ao trabalho, à formação do cidadão, à ética, aos negros, à sustentabilidade, mas em livros didáticos, especialmente, de Geografia, Biologia, História e Sociologia; no segundo bloco, sendo mais específico a esta investigação, foram encontradas dezoito dissertações, os temas principais foram o negro, o meio ambiente, o discurso ecológico, direitos humanos, educação ambiental no livro didático, cidadania, imagens e argumentos ecológicos no livro didático, questão indígena; na terceira busca, Educação Ambiental e Paulo Freire, destaca-se que Freire está, de fato, bem presente nas últimas pesquisas. O pensamento freireano cresce significativamente enquanto suporte teórico para sustentar as ideias no tocante à $E A$, além disso há certo destaque aos temas geradores, corroborando com a pesquisa pretérita de Loureiro e Torres (2014, p.48): "Em síntese, foram investigados 3.774 trabalhos (100\%), dos quais 723 trabalhos (19\%) são de EA escolar. Deste total, apenas 70 estudos (10\%) fazem menção à expressão tema gerador (...)".

Enfim, a primeira etapa de trabalho bibliográfico foi completamente digital, sendo feita uma exploração dos títulos, resumos e algumas dissertações na íntegra, para assim compreender melhor o que publicam acerca das temáticas aqui averiguadas. Seguindo assim o que Marconi e Lakatos prescrevem:

A pesquisa bibliográfica é um apanhado geral sobre os principais trabalhos já realizados, revestidos de importância, por serem capazes de fornecer dados atuais e relevantes relacionados com o tema. $O$ estudo da literatura pertinente pode ajudar a planificação do trabalho, evitar publicações e certos erros, e representa uma fonte indispensável de informações, podendo até orientar as indagações. (MARCONI; LAKATOS, 2003, p. 158) 
Todos os tópicos foram importantes, mas a segunda etapa é mais afim a esta investigação, visto que trabalha com o LD de Língua Portuguesa, assim ela trouxe uma gama de ideias que serviram de objeto temático para análise do livro didático de Língua Portuguesa, por exemplo, meio ambiente e cultura, meio ambiente e cidadania, meio ambiente e tecnologia, meio ambiente e pluralidade educacional, meio ambiente e gêneros textuais, meio ambiente e direitos humanos etc. $O$ estado de arte é um recurso imprescindível, sobretudo, no que se refere ao incremento e aprofundamento da pesquisa.

Portanto, esse trabalho de investigação no catálogo da CAPES evidenciou uma variabilidade significativa de trabalhos que mostraram possibilidades de análise dos livros didáticos, trazendo também argumentos de autoridade que reforçam a construção do trabalho investigativo. Fez ainda compreender melhor a EA ambiental, sobretudo, por meio da ótica Freireana agora utilizada.

\section{Levantamento Bibliográfico atinente à Educação Ambiental}

Nesta averiguação, os destaques vão para os clássicos Pedagogia do Oprimido (1987), Pedagogia da Autonomia (2016), Pedagogia da Indignação (2000), Conscientização (1979), Educação e Mudança (2016) e Medo e Ousadia (1986). Freire deixou um legado imensurável, de modo geral, para educação, que serve também de legado para Educação Ambiental, a citar, as dissertações encontradas que sustentam ideais de cidadania, de participação, de crítica e de emancipação a partir dos escritos do autor.

Os princípios destacados por Freire estão intimamente relacionados aos ideais da EA, Freire enfatiza "discursos lúcidos e em práticas democráticas, que a vontade só se autentica na ação no sujeito que assumem limites" (2000, p.19), destaca: "A consciência do mundo e a consciência de mim me fazem um ser não apenas no mundo, mas com o mundo e com os outros. Um ser capaz de intervir no mundo e não só dele a ele se adaptar" (2000, p.21), e posiciona-se: "Lidar com a cidade, com a pólis, não é uma questão apenas de técnica, mas sobretudo política" (2000, p.22).

Assim, em Pedagogia da Indignação: cartas pedagógicas e outros escritos, ele destaca princípio humanos/sociais que estão à luz do que se fomenta na EA: Ética Humana/Humanização, democracia, diálogo, conscientização e participação ativa (prática), conceitos necessários à diminuição das injustiças, sociais e ambientais, consequentemente, provocando mudanças no mundo.

Enquanto herança, livros foram construídos fundamentados no pensamento freireano e aproveitados aqui, a citar, Educação Ambiental: dialogando com Paulo Freire, organizado por Carlos Loureiro e Juliana Resende Torres (2014). Livro que, entre outros ensinanças, traz a dimensão freireana na Educação Ambiental, a EA na escola e muitas reflexões acerca da questão crítico-transformadora e ético-crítica para escola e para Educação

revista brasileira educação ambiental 
Ambiental. Além dessas questões, o livro mostra a importância da abordagem dos temas geradores na escola, de maneira específica. Nesse sentido:

Por acreditar que a concepção de educação de Paulo Freire possui bases teórico-metodológicas que permitem reorientar as premissas do agir humano no ambiente (na natureza e na sociedade), uma vez que esta concepção de educação encontra-se pautada no homem mundo (FREIRE, 1987) e na dialeticidade sujeito-objeto (representadas nos temas geradores), apresentamos as cinco etapas da dinâmica de Abordagem Temática Freireana que balizam a Organização da Práxis Curricular Interdisciplinar via Temas Geradores (Silva, 2004) via o desenvolvimento de processos formativos e de práticas transformadoras, a fim de contribuir para a área de pesquisa e ação em EA escolar (LOUREIRO; TORRES, 2014, p.56)

Guimarães (2014) destaca ainda que se deve partir de uma consciência individual para uma consciência mais coletiva, mostrando, portanto, que o trabalho é realizado em rede, em debate, em união. Para isso acontecer, deve haver planejamento das ações, pensando em um local que, claro, faz parte de um global, sob uma ótica interdisciplinar, sempre buscando a integração e rechaçando a ideia de fragmentação do saber ambiental. Há um trecho que resume bem a contribuição metodológica de Guimarães:

No trabalho de conscientização é preciso estar claro que conscientizar não é simplesmente transmitir valores "verdes" do educador para o educando; essa é a lógica da educação "tradicional"; é, na verdade, possibilitar ao educando questionar criticamente os valores estabelecidos pela sociedade, assim como os valores do próprio educador que está trabalhando em sua conscientização. É permitir que o educando construa o conhecimento e critique valores com base em sua realidade, o que não significa um papel neutro do educador que negue seus próprios valores em sua prática, mas propicie ao educando confrontar criticamente diferentes valores em busca de uma síntese pessoal que refletirá em novas atitudes (GUIMARÃES, 2014, p.31)

Outra obra pertinente que está à luz do pensamento de Freire é "O que é Educação Ambiental", de Marcos Reigota (2014). São várias explanações concisas sobre como tratar de Educação Ambiental, de tal modo merece destaque a questão do conteúdo, pois "o conteúdo mais indicado é aquele originado do levantamento da problemática ambiental vivida cotidianamente pelos alunos e pelas alunas e que se queira resolver" (REIGOTA, 2014, p.63). Acerca da metodologia de trabalho da EA, Reigota também contribui decisivamente para o processo de análise desta investigação, sobretudo, na Revbea, São Paulo, V. 14, № 2: 306-327, 2019. 
crítica às atividades encontradas nos livros didáticos, bem como para a confecção de atividades do material paradidático, pois a participação é cerne da EA. Segundo Reigota, "a metodologia participativa pressupõe que o processo pedagógico seja aberto, democrático e dialógico entre os próprios alunos e alunas e entre os alunos $e$ as alunas $e$ os professores $e$ as professoras e a administração da escola com a comunidade (...)" (2014, p. 67). Além dessas cooperações, Reigota (2014) ratifica princípios freireanos como diálogo, participação, bem como interdisciplinaridade, mas acrescenta a transversalidade, outrossim destaca a autoavaliação e um distanciamento da avaliação tradicional, pois é inerente à EA a responsabilidade.

\section{Levantamento bibliográfico legislativo e documentos oficiais}

Laconicamente, destacam-se, diante de muitos textos, a Resolução no 2, de 15 de jun de 2012, que estabelece as Diretrizes Curriculares Nacionais para a Educação Ambiental; Lei no 9.795, de 27 de abr. de 1999, dispõe sobre a Política Nacional de Educação Ambiental; e Lei no 9.394 de 20 dezembro de 1996, Lei de Diretrizes e Bases da Educação Nacional (LDBEN).

Enquanto ponto fomentador da pesquisa e convergência com os teóricos apresentados, há que a EA visa a construção de conhecimentos; desenvolvimento de valores sociais, justiça e equidade socioambiental; bem como a EA deve "superar a visão despolitizada, acrítica, ingênua e naturalista ainda muito presente na prática pedagógica das instituições de ensino" (BRASIL, 2012).

Além disso, estimula a mobilidade social, participação individual e coletiva, fortalece a solidariedade, por isso deve ser transversal, contínua e permanente, para assim aprofundar o pensamento crítico-reflexivo.

\section{Levantamento bibliográfico de Língua Portuguesa}

Sobre os teóricos relacionados à Língua Portuguesa, neste caso específico, à linguística, devem ser destacados Mikhail Bakhtin e o livro "Os Gêneros do Discurso" (2016); Luiz Antônio Marcuschi, principalmente, com "Produção Textual, análise dos gêneros e compreensão"(2008) e o capítulo "Compreensão do Texto: algumas reflexões" inserido em "Livro Didático de Português: múltiplos olhares" (2005); Marcos Bagno com o livro "Língua Materna: letramento, variação e ensino"(2002), bem como "Livro Didático de Língua Portuguesa: letramento e cidadania" (2008), de Maria da Graça Costa e Beth Marcuschi. Estes teóricos defendem ideais que são imprescindíveis ao ensino de Língua Portuguesa e relacionam à cidadania, pois colocam a linguagem como recurso de acesso ao conhecimento, uma capacidade humana de articular significados coletivos e compartilhá-los, portanto, essencial ao fomento das práticas sociais, porque não há discurso sem objetivo, isto é, não há discursos vazios e sem um propósito. Da mesma maneira, são os gêneros textuais nos livros didáticos de Língua Portuguesa, cheios de 
ideologias, de crítica e de problematização, não obstante esses textos no tocante à utilização e às atividades não são bem explorados nem fomentam, em grande parte, a prática social e posterior mudança do meio.

Os textos teóricos trazem conceitos do que é texto, discurso, gênero textual e letramento, valores fundamentais para análise dos livros didáticos, pois todas as temáticas relacionadas à Educação Ambiental pertencem a um determinado gênero, segundo Bakhtin (2016, p 12), "tipos relativamente estáveis de enunciados, os quais denominamos gêneros textuais" e segundo Marcuschi (2008, p.155), "os gêneros textuais são os textos que encontramos em nossa vida diária e que apresentam padrões sociocomunicativos característicos definidos por composições funcionais, objetivos enunciativos e estilos concretamente realizados na integração de forças históricas". O linguista Marcuschi (2008) resume bem o pensamento que norteia essa aproximação entre Língua Portuguesa e Educação Ambiental.

Sabe-se ainda que há vários gêneros no $L D$ e estes devem conter temáticas relacionadas à Educação Ambiental, não deve haver exclusivamente a inserção de textos para trabalhar a produção textual e a gramática, pois são instruções do Programa Nacional do Livro Didático (PNLD), sobretudo, trabalhar a cidadania. O Guia de apresentação $(2014$, p.10) traz que os livros didáticos devem trabalhar a formação humana com: "contemplar atividades integradoras de iniciação científica e no campo artístico-cultural vinculadas ao trabalho, ao meio ambiente e à prática social" e "promover estudo e desenvolvimento de atividades socioambientais, conduzindo a Educação Ambiental como uma prática educativa integrada, contínua e permanente" (2014, p.12). De tal forma, percebeu-se que muitos gêneros não desenvolvem adequadamente a EA, assim surgiu a proposta de intervenção, criando, portanto, uma cartilha que promova a Educação Ambiental em uma perspectiva crítico-emancipatória nas aulas de Língua Portuguesa, intitulada "Letramento Ambiental", pois nas palavras de Bagno (2002) e Marcuschi (2008), Letramento é um processo de aprendizagem social e histórico, relacionado a um conjunto de práticas.

\section{Material e Método}

O presente estudo é de caráter documental/bibliográfico e cunho exploratório, visou demonstrar como a Educação Ambiental está sendo aplicada no Livro Didático (LD) de Língua Portuguesa. Sabendo que o LD deve ser escrito à luz de leis educacionais específicas e respeitando os princípios gerais de produção do livro didático, cuja democracia, cidadania e respeito são decisivas à formação dos Estudantes. Sendo assim, fez-se: levantamento bibliográfico de dissertações no Catálogo de Teses e Dissertações da CAPES, porque é importante buscar conhecimento em obras acadêmicas já finalizadas. Desta forma, principalmente, entre os dias 10 a 18 de novembro de 2017 foram inseridas as combinações: (1) Educação Ambiental no livro didático, (2) Educação Ambiental no livro didático de Língua Portuguesa e (3) Educação

Revbea, São Paulo, V. 14, № 2: 306-327, 2019. 
Ambiental e Paulo Freire. Todavia se sabe que os resultados não trazem precisamente o que se busca, mas também dissertações e teses que tangenciam os termos inseridos no buscador. De tal forma, houve um afunilamento para a pesquisa, por exemplo, as teses foram preteridas, uma vez que o interesse maior era nos textos de mestrados, assim estes foram selecionados. Ainda enquanto triagem, foram selecionadas, sobretudo, dissertações dos anos de 2016 e 2017, sendo analisadas entre 10 e 50 páginas do catálogo, sabendo que em cada página há 20 resultados, foram lidos entre 200 e 1000 títulos de cada combinação, sendo que os mais pertinentes à pesquisa fomentaram à busca do texto na íntegra, assim foram lidos os resumos e capítulos oportunos à investigação com o objetivo de analisar cerca de 20 trabalhos.

Referente à verificação bibliográfica atinente à $E A$, principalmente, no tocante a textos escritos a partir dos princípios freireanos, merecem destaque "Educação Ambiental: dialogando com Paulo Freire", organizado por Carlos Loureiro e Juliana Resende Torres (2014); "A Dimensão Ambiental na Educação", de Mauro Guimarães (2014); "O que é Educação Ambiental ", de Marcos Reigota (2014). Sobre Freire os destaques vão para os clássicos Pedagogia do Oprimido (1987), Pedagogia da Autonomia (2016), Pedagogia da Indignação (2000), Conscientização (1979), Educação e Mudança (2016) e Medo e Ousadia (1986).

Houve sondagem bibliográfica relacionada aos textos legislativos e documentos oficiais, haja vista é imprescindível compreender os documentos que fundamentam à EA, por isso a Resolução $n^{\circ}$ 2, de 15 de jun de 2012, que estabelece as Diretrizes Curriculares Nacionais para a Educação Ambiental; o DECRETO no. 73.030, de 30 de out. de 1973; a Lei no .6 .938 , de 31 de ago. de 1981, que dispõe a Política Nacional do Meio Ambiente, seus fins e mecanismos de formulação e aplicação; a LEI no 9.795, de 27 de abr. de 1999, dispõe sobre a Política Nacional de Educação Ambiental; a Lei 9.394 de 20 dezembro de 1996 - Lei de Diretrizes e Bases da Educação Nacional; Carta de Belgrado (1975); e Declaração da Conferência Intergovernamental sobre Educação Ambiental (Tbilisi, 1977) foram pormenorizados.

$\mathrm{Na}$ análise bibliográfica dos livros teóricos acerca do LD de Língua Portuguesa destacam-se Mikhail Bakhtin ${ }^{6}$ e o livro "Os Gêneros do Discurso" (2016); Luiz Antônio Marcuschi, principalmente, com o livro "Produção Textual, análise dos gêneros e compreensão"(2008) e o capítulo "Compreensão do Texto: algumas reflexões" inserido em "Livro Didático de Português: múltiplos olhares" (2005); Marcos Bagno Et al com o livro "Língua Materna: letramento, variação e ensino"(2002), bem como "Livro Didático de Língua Portuguesa: letramento e cidadania" (2008), de Maria da Graça Costa e Beth Marcuschi.

\footnotetext{
${ }^{6}$ Mikhail Mikhailovich Bakhtin foi um filósofo e pensador russo, teórico da cultura europeia e das artes. Estudou em Odessa e Petrogrado, foi professor de história, sociologia e língua russa.
}

revista brasileira educação ambiental 
A análise dos livros da série "Ser Protagonista", inserida no PNLD 2015, organizada por Rogério Ramos, foi realizada de maneira exploratória, houve uma catalogação de cada gênero cuja temática estava relacionada à Educação Ambiental. A finalidade de analisar e criticar o item, sempre destacando como a EA é demonstrada (enquanto temática principal ou acessório para ornamentar a página ou seção) e trabalhada (perspectivas das questões) no livro didático de Língua Portuguesa.

A título de corroboração com a EA nas aulas de Língua Portuguesa foi elaborada uma cartilha, haja vista, há um faraônico propósito em disseminá-la, sobretudo, em escolas de Ensino Médio pois a LP trabalha com textos (gêneros textuais diversos) e eles são o cerne para uma materialização da Educação Ambiental nas escolas e posteriormente na sociedade. A guisa da produção do material paradidático foi pensado no conteúdo, na linguagem adequada ao público, na estrutura gradativa e no layout, por isso foram levados em consideração Robert Bringhurst e sua obra "Elementos do Estilo Tipográfico" (2005), Robin Williams e "Design para quem não é designer: noções básicas de planejamento visual" (1995), bem como Eva Heller com o livro "A Psicologia das cores: como as cores afetam a emoção e a razão" (2013).

\section{Resultado e discussão}

Cabe ainda fazer algumas considerações situacionais do uso da coletânea, principalmente por se tratar do componente curricular de Língua Portuguesa, que geralmente tem a maior carga horária semanal e, consequentemente, anual. De tal forma, nesse componente, há mais tempo para as discussões e, consequentemente, para "formação" de opinião mais cristalizada. No campus Penedo, do Instituto Federal de Alagoas (IFAL), nos dois cursos técnicos integrados ao Ensino Médio, "Açúcar e Álcool" e "Meio Ambiente", as cargas horárias totais dos cursos, envolvendo todas as disciplinas, são respectivamente, 4266,55 e 3993,19, ao passo que a Língua Portuguesa tem maior carga horária total ao final em ambos os cursos, 400h. Em outras palavras, trata-se de um componente que possui uma carga horária elevada e dispõe de um material didático, o qual é entregue a todos os estudantes e utilizado pelos docentes. Assim, indaga-se se essa ferramenta pedagógica contém conteúdos/informações/orientações acerca da EA, pois é necessário saber, obviamente, fazendo um afunilamento, se o livro didático está subsidiando o professor e estudante nessa perspectiva.

Desta forma, foram analisados três livros didáticos ${ }^{7}$ pertencentes à coletânea Ser Protagonista. Todos os cadernos/seções foram apreciados, isto é, etapas da literatura, da produção textual e da gramática. O intento de identificar a EA na perspectiva ecológica, porém, maiormente, política, para

7 RAMOS, Rogério de Araújo. Ser Protagonista: Língua Portuguesa. 2. Ed. São Paulo: Edições SM, 2013. 
assim fazer não só um panorama, mas também criticar e fazer sugestões de aperfeiçoamento, verificando se a EA está à luz do que Reigota (2014) defende, uma educação ambiental política: "(...) está basicamente empenhada na construção e no diálogo de conhecimentos, na desconstrução de representações ingênuas e preconceituosas, na mudança de mentalidade, de comportamentos e de valores e na participação e intervenção cidadã de alunos e das alunas" (REIGOTA,2014, p.73), bem como percebendo se "cada uma dessas áreas de conhecimento tem a sua contribuição para dar à educação ambiental, principalmente quando consegue envolver nas práticas pedagógicas os professores e as professoras de biologia, português, educação artística, geografia, história, inglês, educação física, entre outros" (REIGOTA, 2014, p.64)

Deve-se destacar que a inserção da EA no livro didático é exigida por arcabouços legislativos, por exemplo, o Decreto № 9.099, de 18 de julho de 2017, bem como na Resolução CD/FNDE no $7(2009)^{8}$ que exige boa qualidade do material. No decreto é reiterada a qualidade da educação na etapa básica, principalmente, nas escolas públicas; democratização do acesso às fontes de informação; e, o mais pertinente a esta pesquisa, padrão de qualidade do apoio à prática educativa. Este o mais instigador, porque se sabe que a Educação Ambiental é sim um "conteúdo" que deve estar inserido no livro didático para potencializar a qualidade de um livro.

O Programa do Livro Didático (PNLD) reforça, "a preparação básica para o trabalho e a cidadania do educando, para continuar aprendendo, de modo a ser capaz de se adaptar com flexibilidade a novas condições de ocupação ou aperfeiçoamento posteriores" (BRASIL,1996, p.12).

Essas diretrizes destacam que o livro didático não deve se restringir ao conteúdo específico, em outras palavras, o livro didático de Língua Portuguesa não deve conter exclusivamente informações sobre normas gramaticais e temáticas da literatura. Os textos não podem ser apenas literários e focados em autores e suas estéticas, todavia devem ser variados e, portanto, envolver outras temáticas, as quais possibilitem conhecer mais a sociedade, as regiões do país e proporcionem mais respeito às questões culturais, isto é, tratar das ideologias.

São objetivos fundamentais da educação ambiental: I - o desenvolvimento de uma compreensão integrada do meio ambiente em suas múltiplas e complexas relações, envolvendo aspectos ecológicos, psicológicos, legais, políticos, sociais, econômicos, científicos, culturais e éticos e VII - o fortalecimento da cidadania, autodeterminação dos povos e solidariedade como fundamentos para o futuro da humanidade. (BRASIL, 1999, p.1).

\footnotetext{
${ }^{8} \mathrm{http} / / /$ www.fnde.gov.br/acesso-a-informacao/institucional/legislacao/item/3292resolu\%C3\%A7\%C3\%A3o-cd-fnde-n\%C2\%BAhttp://www.fnde.gov.br/acesso-ainformacao/institucional/legislacao/item/3292-resolu\%C3\%A7\%C3\%A3o-cd-fnde-n\%C2\%BA-7de-20-de-mar\%C3\%A7o-de-2009-alterada-7-de-20-de-mar\%C3\%A7o-de-2009-alterada
} 
No PNLD 2015, há argumentos reforçando a ideia de que o livro didático deve contribuir na preparação para o trabalho e cidadania, e a sustentabilidade socioambiental é colocada como meta universal, outrossim é enfatizado que ela deve ser desenvolvida como prática integrada, contínua e permanente. Conceitos que foram construídos e aprimorados no percurso histórico da Educação Ambiental e assim inseridos nos documentos que norteiam a construção desse importante recurso pedagógico que é o livro didático.

No PNLD de Língua Portuguesa também foram encontradas palavras semelhantes: "desenvolver sua proficiência, seja em usos públicos da oralidade, seja em leitura, em literatura e em produção de gêneros textuais relevantes para a formação escolar, para o ingresso no mundo do trabalho e para o pleno exercício da cidadania" (PNLD, 2014, p.7). Ainda é destacada a justificativa para que a Língua Portuguesa permaneça no ensino médio:

(...) o papel central da língua e da linguagem, tanto nas práticas sociais de diferentes esferas e níveis de atividade humana, quanto na aquisição pessoal de conhecimentos especializados. Ou seja: assim como no ensino fundamental (EF), o desenvolvimento da proficiência oral em situações públicas e, particularmente, da proficiência em escrita, é condição tanto para a formação do aluno como cidadão, como para o desenvolvimento de sua autonomia relativa nos estudos. (PNLD, 2014, p.8).

Outro norteador do processo que destaca a preocupação com a questão humanitária e a participação social é o GUIA do Livro Didático. Então:

Promover a valorização da leitura em todos os campos do saber, desenvolvendo a capacidade de letramento dos alunos; Fomentar o comportamento ético como ponto de partida para o reconhecimento dos deveres e direitos da cidadania, e para a prática de um humanismo contemporâneo expresso pelo reconhecimento, respeito e acolhimento identitário e pela incorporação da solidariedade; Promover estudo e desenvolvimento de atividades socioambientais, conduzindo a Educação Ambiental como uma prática educativa integrada, contínua e permanente; (...) (GUIA DE LIVROS DIDÁTICOS, 2014, p.13).

Há alguns pontos inerentes a esta seção que merecem ser reforçados, uma vez que este trabalho se fundamenta em três grandes áreas/princípios para análise dos livros didáticos.

O primeiro, e mais determinante, a Educação Ambiental, objeto da pesquisa, que questiona algumas convicções, que suscita novas metodologias, envolve os conteúdos ambientais à prática. Uma ação que envolva, de fato, o homem com o meio, promovendo, como afirma Guimarães (2014, p.15), "uma 
relação harmoniosa, consciente do dinâmico na natureza, que possibilite, por meio de novos conhecimentos, valores e atitudes, a inserção do educando e do educador como cidadãos no processo de transformação do atual quadro ambiental do nosso planeta". Lembrando que a EA aqui priorizada é a mesma defendida por Reigota (2014, p.13) "A educação ambiental como educação política está comprometida com a ampliação da cidadania, da liberdade, da autonomia e da intervenção direta dos cidadãos e das cidadãs na busca de soluções e alternativas que permitam a convivência digna e voltada para o bem comum".

O segundo ponto está relacionado aos ensinamentos freireanos, haja vista Freire foi defensor da democracia, da humanidade, da igualdade, do respeito, da crítica entre outros que convergem aos princípios da EA. Ensinamentos esses suscitados a partir de temas geradores, segundo Freire (1987), eles proporcionam uma importante relação entre os homens e o mundo. Desta forma, procurou-se analisar os gêneros textuais e atividades nos livros didáticos de Língua Portuguesa que proporcionassem essa melhor relação e não apenas exercício que fossem, grosso modo, mecânicos. Em outras palavras, segundo Freire:

Enquanto na prática "bancária" da educação, anti-dialógica por essência, por isto, não comunicativa, o educador deposita no educando o conteúdo programático da educação, que ele mesmo elabora ou elaboram para ele, na prática problematizadora, dialógica por excelência, este conteúdo, que jamais é "depositado", se organiza e se constitui na visão do mundo dos educandos, em que se encontram seus "temas geradores" (FREIRE, 1987, p.58).

Assim os ideais de Freire, muito bem recebidos pela Educação Ambiental - e deveriam ser -, foram buscados no livro didático de Língua Portuguesa. De tal forma, indagações foram suscitadas para nortear o trabalho, a citar, há sim no livro didático de Língua Portuguesa uma EA ambiental "bancária"? Ou pior, a EA/MA aparece apenas como um item para cumprir as normas e apenas adornam os livros didáticos de Língua Portuguesa? Lembrando ainda que Freire (1987, p.37) afirma que a "fonte geradora na ação sobre o mundo, o qual mediatiza as consciências em comunicação, não será possível a superposição dos homens aos homens" e ainda:

A investigação dos "temas geradores" ou da temática significativa do povo, tendo como objetivo fundamental a captação dos seus temas básicos, só a partir de cujo conhecimento é possível a organização do conteúdo programático para qualquer ação com ele, se instaura como ponto de partida do processo da ação, como síntese cultural (FREIRE, 1987, p.105).

Revbea, São Paulo, V. 14, № 2: 306-327, 2019.

revista brasileira educação ambiental 
Freire (1987) traz, já destacado acima, a igualdade, o diálogo e investigação como pontos importantes para construção de um mundo melhor. Não sendo a favor da alienação, da ação desumana, mas sim que fomente a liberdade de pensamento em prol de um mundo melhor a todos, ou seja, a transformação. O que ele chama de educação libertadora. Tudo o que se precisa para uma Educação Ambiental melhor, potencializadora.

O terceiro, os princípios linguísticos, sobretudo, relacionados ao que escreveu Bakhtin (2016) e Marcuschi (2008). O primeiro por trazer essa ideia de gêneros do discurso, ao passo que o segundo adaptou esse conceito à realidade educacional brasileira no sentido do ensino de língua para a comunicação ativa dos estudantes. Sobre Marcuschi, vale ressalta que ele fez inúmeros trabalhos voltado para a linguística, mas para análise do livro didático de Língua Portuguesa em consonância com EA foi bem pertinente o artigo, cujo título é "Compreensão de texto: algumas reflexões", que está inserido no livro intitulado "Livro Didático de Português: Múltiplos Olhares" (2005). O trabalho faz, nas possibilidades de um artigo, uma vultosa análise sobre o livro didático, tendo como consideração que: "os exercícios de compreensão raramente levam a reflexões críticas sobre o texto e não permitem expansão ou construção de sentido (...)" (DIONÍSIO; BEZERRA, 2005, p. 51). Além disso, o linguista enumerou nove (9) tipos de perguntas comuns nos livros didáticos de Língua Portuguesa, as quais serviram de método para análise das perguntas, quando a pauta estivesse relacionada à Educação Ambiental: $\mathrm{A}$ cor do cavalo branco de Napoleão; Cópias; Objetivas; Inferenciais; Globais; Subjetivas; Valetudo; Impossíveis; e metalinguísticas. Ele demonstra que a maioria das perguntas não desenvolve o senso crítico e a capacidade de análise, por exemplo, são exigidas cópias de fragmentos dos textos e outras que podem ser respondidas de qualquer maneira (vale-tudo). No tocante as "subjetivas", que deveriam fomentar a reflexão e crítica, Marcuschi fala que os estudantes não tomam uma decisão, eles, na verdade, respondem para agradar à professora, "Quanto às perguntas subjetivas, é bom ter presente que os alunos se sentem comprometidos com o paradigma da escola e às vezes dizem que imaginam que vai agradar à professora" e "(...) temos uma situação que não contribui para a formação do raciocínio crítico" (DIONíSIO; BEZERRA, 2005, p.56). Ainda na pesquisa realizada por Marcuschi, há um dado preocupante, "somente um décimo das questões situaram-se na classe de perguntas que exigem reflexão mais acurada, ou seja, algum tipo de inferência ou raciocínio crítico" (Dionísio e Bezerra, 2005, p.57). Não fora realizada uma catalogação de questões da mesma dimensão que Marcuschi, mas foram analisadas questões relacionadas aos gêneros que tinham temática da EA/MA e fora percebido o que, de fato, Marcuschi destacava, questões superficiais e, na maioria das situações, não abordavam os princípios da EA.

Assim, em blocos, os três livros da série SER PROTAGONISTA foram analisados, levando em consideração o que foi exposto no início desta seção, bem como na fundamentação, outrossim considerando o impetrado pelo PNLD e demais documentos norteadores da produção do livro didático que, 
sobretudo, destaca BRASIL (1996, p.12), "a preparação básica para o trabalho e a cidadania do educando, para continuar aprendendo, de modo a ser capaz de se adaptar com flexibilidade a novas condições de ocupação ou aperfeiçoamento posteriores". Fazendo a averiguação, fora percebido que o volume primeiro possui 400 páginas, número significativo para um material do primeiro ano, está dividido em 15 unidades, havendo 33 capítulos. Foram catalogadas vinte e três (23) seções que contém gêneros sobre a EA/MA, sendo catalogados 102 gêneros do tipo textual, imagético e misto (vocábulos e imagens).

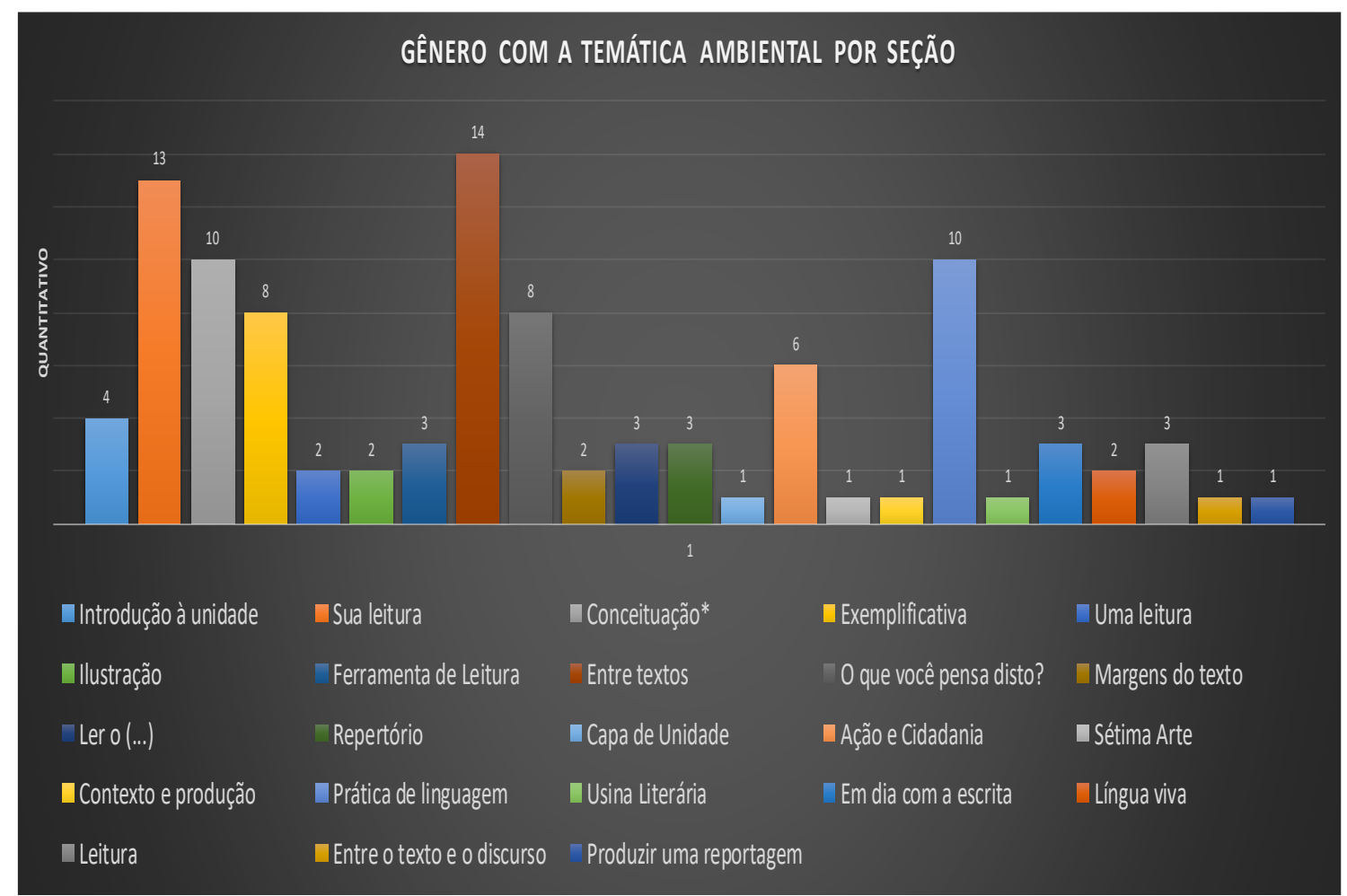

Figura 1: Análise do primeiro volume coletânea Ser Protagonista, PNLD 2015 Fonte: Pesquisador (2018)

A princípio, uma hipótese foi suscitada, a de que havia poucos gêneros que tratavam da EA/MA, todavia, em quantidade esse pressuposto foi superado, pois o primeiro volume da coleção está repleto de textos relacionados à temática ambiental. Em síntese, foram encontrados mais de 100 gêneros textuais associados à EA/MA, no entanto, muitos serviram para ornamentar o livro didático, principalmente, no início dos capítulos, unidades e margens dos livros. Além disso, mesmo os textos sendo fartos para discussão, não foram aproveitados com profundidade, pois as perguntas eram introdutórias e não fomentavam o raciocínio crítico e, consequentemente, transformações. Ratificando o que Marcuschi havia dito, "os exercícios de compreensão raramente levam a reflexões críticas sobre o texto e não permitem expansão ou construção de sentido (...)" (DIONÍSIO; BEZERRA, 2005 p. 51). 
No segundo volume, livro de 392 páginas que seguiu a mesma linha de organização do primeiro volume, haja vista faz parte de um todo que é a série Ser Protagonista. Enquanto característica tem-se um livro bem colorido, repleto de imagens e textos, bem como carregado de atividades. Foram analisados todos os capítulos e unidades, assim foram catalogados 100 gêneros textuais, imagéticos e mistos relacionados à EA/MA. Os gêneros foram utilizados de diversas formas nas vinte e quatro (24) seções registradas. Entre estas, destacam-se, no aspecto quantitativo, "O que você pensa disto", com 14 textos; a seção "Explicação" - utilizada para explicar o conteúdo -, foram encontrados 13 exemplos; no segmento "Ação e cidadania" foram encontrados 9 exemplos. A seção "Prática de Linguagem" contemplou sete (7) vezes a questão ambiental, trazendo também algo digno de apreciação:

5. Examine o texto a seguir, extraído de uma propaganda.

Votar para presidente, expressar sua opinizão sem medo, manifestar posições políticas contrárias ao governo, entrar e sair do pais livremente. 0 que hoje parece tão simples e natural marcou toda uma geração que sofreu com a repressão num passado não distante. Conhecer a luta do povo brasileiro para recuperar a democracia é a melhor forma de impedir que erros do passado se repitam no futuro.

a) Como a fotografia que compõe o fundo da propaganda se relaciona ao slogan (escrito em letras maiores, com fundo azul)?

b) Observe o contraste entre as cores da foto e as do logotipo no canto inferior direito da propaganda. Que efeito esse contraste produz?

c) Qual parece ser a finalidade desse texto? Em que ele se diferencia de um anúncio publicitário? Explique.

d) Em que nível da língua você precisou analisar a propaganda para responder às questôes anteriores? Justifique.

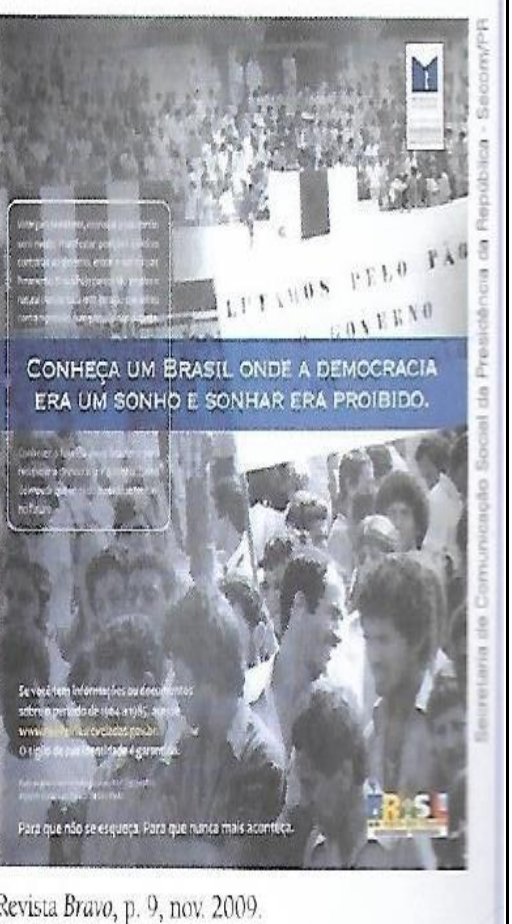

Figura 2: Exercício acerca de gênero textual com temática ambiental Fonte: Pesquisador (2018)

Há cinco (5) questões, sendo a última bastante pertinente ao que se investiga aqui. Trata-se de uma questão elaborada com a finalidade de trabalhar a linguagem, sobretudo, relacionada à propaganda (publicidade), no entanto, as perguntas não são direcionadas aos assuntos como democracia, liberdade e ditadura presentes no gênero, o que acontece mesmo é uma abordagem pouco preocupada com as questões ideológicas. Essa situação faz remeter a Freire: 
O intelectual memorizador, que lê horas a fio, domesticando-se ao texto, temeroso de arriscar-se, fala de suas leituras quase como se estivesse recitando-as de memória - não percebe, quando realmente existe, nenhuma relação entre o que leu e o que vem ocorrendo no seu país, na sua cidade, no seu bairro (FREIRE, 2016, p.29).

O que se percebe, de maneira ampla, quando aparecem temáticas ligadas à EA/MA, são seções complementares, aparentemente sem muita importância, pois vem no rodapé ou às margens das páginas, passando também uma ideia de adorno que, de fato, muitas vezes é, principalmente quando foram colocadas árvores, flores e alguns animais para ilustrar a página. E preciso que os livros estejam recheados de qualidade, para fomentar nos educandos novas posturas, para assim haver transformação da sociedade e, portanto, do mundo.

A escola tem sido historicamente o espaço indicado para a discussão e o aprendizado de vários temas urgentes e de atualidade como resultado da sua importância na formação dos cidadãos. É evidente que a escola deve estar sempre aberta ao conhecimento, inquietações e propostas de sua época, procurando consolidar inovações pedagógicas que contribuem para continuar cumprindo seu papel social (REIGOTA, 2011, p.81).

No terceiro volume, seguramente, foram encontrados 68 gêneros atinentes à EA/MA em várias unidades e seções. Dentre as seções (total de 18), que tiveram mais gêneros com a temática da EA/MA, liderou "Sua leitura", com 14; "O que você pensa disto", com 8; "Exemplificação", com 7. Percebeuse que as temáticas poderiam ser trabalhadas com mais qualidade, haja vista são bons textos. Vale frisar que uma seção chamou bastante atenção, na verdade, trata-se de unidades diferentes, são os "Projetos", unidades que tratam do debate, da crítica e do trabalho coletivo, algo que se aproxima da EA moderna. As demais trabalham numa perspectiva bastante bancária, com perguntas que não fomentam a crítica, como já destacadas por Marcuschi, são objetivas, metalinguísticas e vale-tudo.

Portanto, foram analisados os três (3) volumes de a série "Ser Protagonista", livros que foram escolhidos pelo Instituto Federal de Alagoas e utilizado no campus Penedo. A coleção faz parte do triênio do PNLD que iniciou no ano de 2015 e se estendeu até 2017, ano que iniciou essa pesquisa. No PNLD de apresentação é frisado que foram dezessete (17) obras avaliadas, porém apenas dez (10) aprovadas e resenhadas para apreciação, entre estas a coleção "Ser Protagonista". Estes livros precisavam conter alguns "elementos" para serem relacionados, logo na página onze (11) do PNLD Apresentação eles são destacados, a citar, preparação para cidadania, aprimoramento do 
educado como pessoa humana, formação ética e desenvolvimento do pensamento crítico, além desses elementos imprescindíveis, outros são destacados no corpo do texto, por exemplo, direitos humanos e sustentabilidade socioambiental. Em outras palavras, o livro didático para estar inserido no catálogo deveria estar em consonância com os princípios da Educação Ambiental e foi em busca disso que essa investigação se debruçou, porém percebeu o não cumprimento qualitativo dessas questões, ao passo que quantitativamente percebeu-se um número expressivo, foram catalogados, entre as mais variadas unidades, capítulos e seções dos livros, 270 textos que traziam como temática assuntos atinentes ao Meio Ambiente e Educação Ambiental, sendo 102 gêneros no volume primeiro, 100 no volume segundo e 68 no volume terceiro, porém, ratifica-se que o realizado a partir desses textos é algo bem superficial, sobretudo, à medida que a análise prosseguia sobre os últimos volumes, porque se verificou ainda que as indagações eram bastante propedêuticas para estudantes mais experientes.

\section{Considerações}

Esta pesquisa objetivou analisar como a Educação Ambiental (Meio Ambiente) é desenvolvida no livro didático de Língua Portuguesa, proeminente recurso de subsídio ao ensino de Língua Portuguesa para os estudantes dos cursos técnicos de "Meio Ambiente" e "Açúcar e Álcool" integrados ao Ensino Médio, adotado pelo campus Penedo, do Instituto Federal de Alagoas, para o triênio 2015, 2016 e 2017.

O que se percebeu não foi o descumprimento, mas a falta de proficuidade acerca da temática, uma vez que os exercícios trabalhados são bastante propedêuticos. Veem-se atividades que tratam de cidadania (EA) ainda de maneira ilustrativa e de pouca reflexão, claro que isso não se dá nos três volumes da coleção em sua totalidade, haja vista há alguns exemplos bem críticos-reflexivos discutidos. Outrossim, destaca-se que nem tudo pode ser criticado negativa, porque a variabilidade de textos informativos relacionados à Educação Ambiental e à cidadania são significativos, isso no que se refere aos três anos e em todas as seções.

Além disso, há sempre uma contextualização da situação para relacionar às questões linguísticas e/ou literárias com a promoção da política, da saúde, da ecologia etc. Outro ponto relevante são as sugestões de leitura de textos, filmes e documentários, ação essa que fomenta, com certeza, o acesso ao conhecimento crítico-emancipatório, pois o discente fará as próprias reflexões e relacionará a questões conteudísticas. Algo que foi aprimorado no material paradidático produzido a partir desta pesquisa.

Diante das situações detectadas, observou-se a necessidade de mais investigações direcionadas a analisar como o livro didático de Língua Portuguesa trata a $E A$, pois muitas estão relacionadas às disciplinas de Geografia, Biologia e História. Deve-se averiguar como os textos estão dispostos, como as questões são contextualizadas e se a preocupação é Revbea, São Paulo, V. 14, № 2: 306-327, 2019. 
exclusivamente ecológica. Deve-se cada vez mais criticar os livros para que sejam feitas melhorias nas posteriores publicações, porque os LD estão com uma quantidade significativa de textos interessantes, porém muitas vezes incluídos de maneira secundária e, sobretudo, mal utilizados, com perguntas elementares e não relacionadas ao cerne da questão, ou seja, a ideologia. O livro didático é um grande formador de opinião e, entre outros inúmeros motivos, não pode no tocante à EA ser utilizado de maneira superficial, ingênua, descontextualizada das questões sociais, desconexa à região, acrítica e mecânica. A EA precisa ser trabalhada num viés dialógico e solidário, promovendo a articulação de conhecimentos e sujeitos, sempre pautada na crítica, de maneira interdisciplinar e transversal, promovendo ações para mitigar problemas criados no passado, promover melhorias para o presente e para as futuras gerações. Lembrando o que disse Freire (2016, p.101) "a memorização mecânica do perfil do objeto não é aprendizado verdadeiro do objeto ou do conteúdo" e "uma educação que procura desenvolver a tomada de consciência e a atitude crítica, graças à qual o homem escolhe e decide, liberta-o em lugar de submetê-lo, de domesticá-lo, de adaptá-lo" (FREIRE, 1979, p. 19).

\section{Referências}

BAKHTIN, M.. Os gêneros do discurso. São Paulo: Editora, 2016.

BAGNO, M. et al. Língua Materna: letramento, variação e ensino. São Paulo: Parábola, 2002.

BRASIL. LEI n. 9795, de 27 de abr. de 1999. Política Nacional de Educação Ambiental . Política Nacional de Educação Ambiental. FERNANDO HENRIQUE CARDOSO. 1. ed. Brasília, v. 1, p. 1-5, abr. 1999. Disponível em: <http://www.planalto.gov.br/ccivil_03/leis//9795.htm>. Acesso em: 20 dez. 2017.

BRASIL. Lei 9.394 de 20 dezembro de 1996 - LDB-Lei de Diretrizes e Bases da Educação Nacional. Curitiba: Universidade Federal do Paraná, 1997.

BRASIL. Ministério da Educação e do Desporto. Parâmetros curriculares nacionais: meio ambiente, saúde. Brasília: Secretaria de Educação Fundamental, 1997.

BRASIL. Ministério do Meio Ambiente. DECLARAÇÃO DE TBILISI. Brasília/DF, [1992?\}. Disponível em: <http://www.mma.gov.br/port/sdi/ea/deds/pdfs/decltbilisi.pdf Acesso em: $01 \mathrm{de}$ novembro de 2017.

BRASIL. Parâmetros Curriculares Nacionais: Meio Ambiente e Saúde. Secretaria de Educação Fundamental. 2 ed. Rio de Janeiro: DP\&A, 2000. ISBN 85-86589-76-2 
BRASIL. RESOLUÇÃO № 2, DE 15 DE JUNHO DE 2012. Estabelece as Diretrizes Curriculares Nacionais para a Educação Ambiental. Brasília. Resolução CNE/CP 2/2012. Diário Oficial da União, Brasília, 18 de junho de 2012 - Seção 1 - p. 70. Disponível em: http://portal.mec.gov.br/docman/ agosto-2017-pdf/70431-res-cne-cp-002-03072015-http://portal.mec.gov.br/ docman/agosto-2017-pdf/70431-res-cne-cp-002-03072015-pdf/filepdf/file $>$ Acesso em: 26 de ago. 2017.

BRASIL. Secretaria de Educação Fundamental. Parâmetros curriculares nacionais: terceiro e quarto ciclos do ensino fundamental: língua portuguesa/ Secretaria de Educação Fundamental. Brasília: MEC/SEF, 1998.

BRINGHURST, Robert. Elementos do Estilo Tipográfico. Tradução de André Stolarski. Cosac Naify, 2005.

DIONÍSIO, A.P.; BEZERRA, M.A. O livro didático de Português: múltiplos olhares. Rio de Janeiro: Lucerna, 2005. 3 ed. ISBN: 85-86930-14-8

HELLER, E. A Psicologia das cores: como as cores afetam a emoção e a razão. Tradução: Maria Lúcia Lopes da Silva. 1 ed, São Paulo: Gustavo Gili, 2013.

FREIRE, P. Conscientização: teoria e prática da libertação. São Paulo: Cortez e Moraes, 1979.

FREIRE, P. Pedagogia da Autonomia: Saberes necessários à prática educativa. 54. ed. Rio de Janeiro: Paz e Terra. 2016.a

FREIRE, P. Educação e Mudança. 37ำ ed. São Paulo: Paz e Terra, 2016.b

FREIRE, P. Pedagogia da Indignação: cartas pedagógica e outros escritos. São Paulo: Unesp, 2000. ISBN: 85 - 7139 - 291 - 2

FREIRE, P. Pedagogia do Oprimido. $17^{\mathrm{a}}$ ed. Rio de Janeiro: Paz e Terra, 1987.

FREIRE, P.; SHOR, I. Medo e Ousadia: O Cotidiano do Professor. Rio de Janeiro: Paz e Terra, 1986.

GONÇALVES, H.A. Manual de Artigos científicos. 2. ed. São Paulo: Avercamp, 2013. ISBN: 9788589311670.

GUIA DE LIVROS DIDÁTICOS. PNLD 2015: apresentação : ensino médio. Brasília : Ministério da Educação, Secretaria de Educação Básica, 2014.

GUIA DE LIVROS DIDÁTICOS: PNLD 2015: língua portuguesa : ensino médio. - Brasília: Ministério da Educação, Secretaria de Educação Básica, 2014.

GUIMARÃES, M. A dimensão ambiental na educação. 11. ed. Campinas, SP. Papirus. 2014.

LAKATOS, E.M.; MARCONI, M.A. Fundamentos de Metodologia Científica. 5. ed. São Paulo: Editora Atlas, 2003. ISBN: 85-224-3397-6 LOUREIRO, C.F.B.; TORRES, J.R. (Org.). Educação Ambiental: dialogando com Paulo Freire. 1. ed. São Paulo: Cortez, 2014.

Revbea, São Paulo, V. 14, No 2: 306-327, 2019. 
MARCUSCHI, L.A. Produção Textual, análise de gêneros e compreensão. São Paulo: Parábola, 2008.

MARCUSCHI, L.A. Gêneros Textuais: definição e funcionalidade. Disponível em https://edisciplinas.usp.br/resource/wiew Acesso em: 20 de ago de 2017.

RAMOS, R.A. Ser Protagonista: Língua Portuguesa (1ํano - Ensino Médio). 2. Ed. São Paulo: Edições SM, 2013.

RAMOS, R.A. Ser Protagonista: Língua Portuguesa (2으 ano - Ensino Médio). 2. Ed. São Paulo: Edições SM, 2013.

RAMOS, R.A. Ser Protagonista: Língua Portuguesa (3 ano - Ensino Médio). 2. Ed. São Paulo: Edições SM, 2013.

REIGOTA, M. Meio Ambiente e representação social. 8. ed. São Paulo: Cortez, 2010.

REIGOTA, M. O que educação ambiental? 2. ed. São Paulo: Brasiliense, 2014.

VAL, M.G.C.; MARCUSCHI, B. (Org.). Livros didáticos de língua Portuguesa: letramento e cidadania. Belo Horizonte: Ceale, 2008.

WILLIAMS, R. Design para quem não é designer: noções básicas de planejamento visual. Tradução Laura Karin Gillon. São Paulo: Callis, 1995. 8 edição 